\title{
Methane Production from Glucose by a Mixed Culture of Bacteria in the Chemostat: the Role of Citrobacter
}

\author{
By FAUSTINO SIÑERIZ* AND S. JOHN PIRT \\ Microbiology Department, Queen Elizabeth College (University of London), \\ Campden Hill, London W8
}

(Received 4 February 1977)

A chemostat culture under a nitrogen atmosphere with a formate and inorganic salts medium fed at dilution rates up to $0 \cdot \mathrm{I} \mathrm{h}^{-1}$ and inoculated from a sewage works anaerobic digester, proved to be an easy way of isolating a stable methanogenic bacterial culture. Formate-limited growth yielded a mixed culture containing predominantly methanogenic bacteria morphologically similar to Methanobacterium formicicum and Methanobacterium ruminantium.

When glucose was substituted for formate, a facultative anaerobe capable of metabolizing glucose was selected. This species far outnumbered any other on aerobically incubated nutrient agar and was identified as a species of Citrobacter. The main products of glucose fermentation by this citrobacter were acetate, formate, ethanol and lactate. When the spent medium from the citrobacter fermentation of glucose was fed to the methanogenic culture, formate and lactate appeared to be the substrates which limited methane production. When each of the citrobacter products (acetate, ethanol and lactate) was fed as the sole carbon source to a methanogenic culture selected by growth on formate, lactate by itself could maintain methane production, but acetate and ethanol by themselves were not substrates for methane production. Lactate is thus a major intermediate in the conversion of glucose to methane by the mixed culture.

\section{INTRODUCTION}

Knowledge of the physiology of the methanogenic bacteria is slight despite the increasing importance of these anaerobes for the production of a clean energy and carbon source from organic wastes. Most research in the field is concerned with empirical means of exploiting anaerobic digestion of wastes of undefined composition, such as manure, rather than elucidating the basic mechanisms whereby different types of compounds are converted to methane. Studies on methanogenesis require chemically-defined culture media for definition of both the substrates and the essential microbial species. An example of such a basic study is that by Ferry \& Wolfe (1976) on degradation of benzoate to methane. Our work has been concerned with the anaerobic digestion of glucose to methane to establish how glucose could be transformed into methane and what type of microbial population would be involved in the process. Whereas Ferry \& Wolfe (I976) used batch culture we have used chemostat culture for the process. The chemostat method offered the advantage of producing time-independent steady states which simplify the system and facilitate identification of rate-limiting factors.

* Present address: New York State Department of Health, New Scotland Ave, Albany, New York I 220 I, U.S.A. 


\section{METHODS}

Apparatus. A chemostat ( $200 \mathrm{ml}$ Pyrex glass culture vessel) similar to that described by Pirt \& Callow (1964) was used. The medium flow was controlled by a flow inducer (model HR; Watson Marlow, Falmouth, Cornwall). All the connexions were made with butyl rubber tubing and the anaerobic conditions were maintained by passing a slow stream (about $10 \mathrm{ml} \mathrm{min}^{-1}$ ) of sterile $\mathrm{O}_{2}$-free nitrogen over the culture. The medium reservoirs were also kept under nitrogen. The separation of the gaseous and liquid phases at the outlet of the culture vessel was achieved through a $2 \mathrm{ml}$ syphon (Fig. I) which allowed a precise measurement of the medium flow. At the same time the syphon seal ensured a small gas space (less than $250 \mathrm{ml}$ ) so that equilibrium within the gas phase was reached quickly even at low gas flow rates. Samples of the gas phase were taken by puncturing the tubing with a sterile 25 gauge needle and syringe. The culture temperature was $37^{\circ} \mathrm{C}$. Strict asepsis was maintained in all cultures.

Medium. Chemostat culture medium, based on PI (Pirt, I975; p. 134), contained $\left(\mathrm{g} \mathrm{l}^{-1}\right): \mathrm{NH}_{4} \mathrm{Cl}$, $2 \cdot 2 ; \mathrm{KH}_{2} \mathrm{PO}_{4}, \mathrm{I} \cdot 13 ; \mathrm{NaH}_{2} \mathrm{PO}_{4} .2 \mathrm{H}_{2} \mathrm{O}, \mathrm{I} \cdot 56 ; \mathrm{Na}_{2} \mathrm{HPO}_{4} \cdot 2 \mathrm{H}_{2} \mathrm{O}, 7 \cdot 12 ; \mathrm{MgSO}_{4} .7 \mathrm{H}_{2} \mathrm{O}, 0.23 ; \mathrm{CaCl}_{2} .2 \mathrm{H}_{2} \mathrm{O}$, $0.01 \mathrm{I} ; \mathrm{FeSO}_{4} .7 \mathrm{H}_{2} \mathrm{O}$, 0.0I4; $\mathrm{MnSO}_{4} .4 \mathrm{H}_{2} \mathrm{O}, 0.002 ; \mathrm{ZnSO}_{4} .7 \mathrm{H}_{2} \mathrm{O}, 0.002 ; \mathrm{CuSO}_{4} .5 \mathrm{H}_{2} \mathrm{O}$, 0.0004 ; $\mathrm{CoCl}_{2} .6 \mathrm{H}_{2} \mathrm{O}, 0.0004$; and EDTA (disodium salt), $0.08 \mathrm{I}$. (All the trace elements including $\mathrm{Ca}^{2+}$ were kept as a $100 \times$ concentrated solution in EDTA, neutralized with $\mathrm{NaOH}$ to $\mathrm{pH} 7 \cdot 2)$. Resazurin $\left(0 \cdot 00 \mathrm{I}^{-1}\right)$ was added as a redox indicator and $\mathrm{Na}_{2} \mathrm{~S} .9 \mathrm{H}_{2} \mathrm{O}\left(0.25 \mathrm{~g} \mathrm{1}^{-1}\right)$ was used to reduce the medium. The carbon source was added in the concentrations indicated for the different experiments. The $\mathrm{pH}$ in the culture was kept in the range $7 \cdot 2$ to $7 \cdot 4$ by automatic addition of I $\mathrm{M}-\mathrm{NaOH}$ or $0.5 \mathrm{M}-\mathrm{H}_{2} \mathrm{SO}_{4}$.

Peptone agar, $\mathrm{pH} 7 \cdot 2$, contained $\left(\mathrm{g}^{-1}\right)$ : peptone, $\mathrm{IO} ; \mathrm{NaCl}, 5$; and agar, 20.

Analyses. Formate and acetate were determined by titration with $\mathrm{KOH}$ after separation in a silicic acid column (Ramsey, 1963). Glucose was measured by the glucose oxidase method (Biochemica Test Combination, Boehringer) and ethanol was also determined enzymically (Biochemica Test Combination). Lactate was measured by the method of Barker \& Summerson (I94r). Methane was determined in a Pye Unicam I04 gas chromatograph equipped with a column of silica-gel $(150 \times 0.4 \mathrm{~cm})$ and using nitrogen as the carrier gas. The results were quantified by comparing the areas with those of a standard mixture of $\mathrm{CH}_{4} / \mathrm{CO}_{2}$. Total numbers of bacteria were counted in a Coulter counter; viable Escherichia coli organisms were enumerated on MacConkey agar (Oxoid) plates incubated aerobically.

Electron microscopy. The procedure described by Zeikus \& Bowen (1975) was used.

\section{RESULTS AND DISCUSSION}

\section{Continuous culture on formate}

To isolate a methanogenic culture able to grow on the defined medium, a sample of sludge from an anaerobic digester was used to inoculate a chemostat supplied with formate medium. The sample was taken from one of the digesters which is operated by the Thames Water Authority and produces methane in the Mogden plant (Twickenham, London). The raw sample was left to settle overnight and $20 \mathrm{ml}$ of the supernatant fluid was introduced into the culture vessel of the chemostat; a slow flow of medium was started (dilution rate, $D=0.02 \mathrm{~h}^{-1}$ ) and methane production was recorded until it remained constant. A slow flow of medium was important because many micro-organisms possess a formatelyase system which, in a chemostat like ours where the gaseous products were swept away, would deplete the carbon source by the reaction: formate $\rightarrow \mathrm{CO}_{2}+\mathrm{H}_{2}$. Once a culture became established the dilution rate was increased to $0.08 \mathrm{~h}^{-1}$ to wash out organisms other than those utilizing formate. Thus we obtained a methanogenic mixed culture which was stable indefinitely (longer than 6 months) in the chemostat. The characteristics of this culture are described below.

Methane production by the mixed culture grown on various concentrations of formate in the chemostat varied over a range of dilution rates (Fig. 2). With formate up to $66 \mathrm{~mm}$ in the incoming medium, methane production behaved as a formate-limited growth-linked process with good agreement between the theoretical and experimental values. The average efficiencies for the conversion of formate to methane, as percentages of the theoretical values, were: $103 . \mathrm{I} \pm \mathrm{I} 6.6$ (mean of five), $94.3 \pm \mathrm{I} 4.2$ (mean of five) and $97.7 \pm$ II .6 (mean of three) for 25,50 and $66 \mathrm{~mm}$-formate respectively. The biomass was too low for direct 


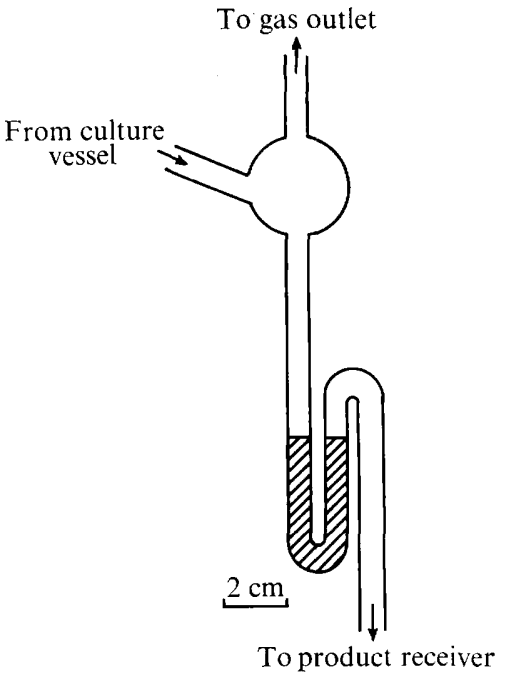

Fig. I

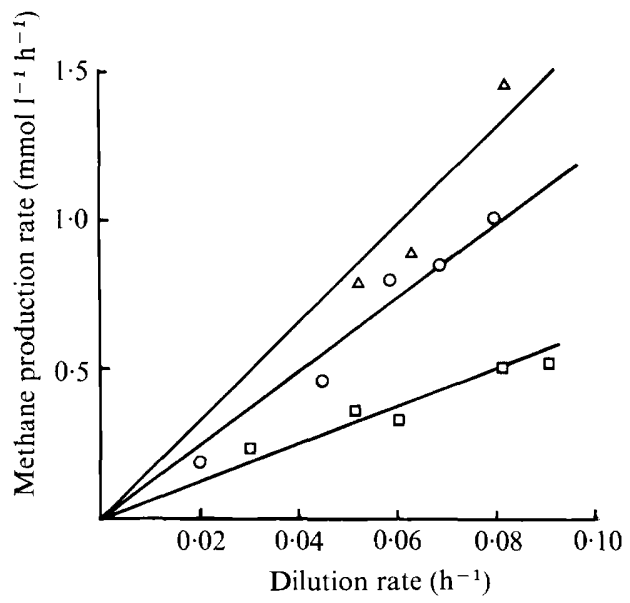

Fig. 2

Fig. I. Diagram of the syphon used to separate gaseous and liquid phases of the culture. The syphon fitted in the neck of the harvest bottle.

Fig. 2. Methane production in chemostat culture on formate. The culture was run at different dilution rates $(D)$ until steady-state conditions (constant rate of methane production) were achieved with formate at $25 \mathrm{mM}(\square), 50 \mathrm{~mm}(\bigcirc)$ or $66 \mathrm{mM}(\triangle)$. The lines represent, for each formate concentration, the theoretical values for complete conversion of formate to methane according to the equation: $4 \mathrm{HCOOH} \rightarrow \mathrm{CH}_{4}+3 \mathrm{CO}_{2}+2 \mathrm{H}_{2} \mathrm{O}$. The culture was washed out at $D=0 \cdot \mathrm{I} \mathrm{h}^{-1}$.

measurement but from the slight turbidity of the culture it was inferred that the cell carbon was negligible compared with the methane carbon. The maximum specific growth rate, which equals the critical dilution rate (Pirt, 1975), was between 0.09 and $0 . \mathrm{h} \mathrm{h}^{-1}$, hence the minimum doubling time was 7 to $8 \mathrm{~h}$.

\section{Morphology of the bacteria present in the continuous culture on formate}

Most methanogenic bacteria in pure culture studied so far have similar requirements with respect to substrate, i.e. most can use formate and/or $\mathrm{CO}_{2}$ plus $\mathrm{H}_{2}$. Under our conditions, no selection of a single morphological type occurred: the two main types of organism recognized as methanogenic bacteria are shown in Fig. 3. Since formate cannot be used anaerobically as a growth substrate by other types of bacteria, we deduce that most of the bacteria present in the culture were methanogenic. One species was a long rod, usually in pairs or chains and sometimes with no septa, similar to Methanobacterium formicicum (Wolfe, 197I) and the other was a diplococcus similar to Methanobacterium ruminantium (Wolfe, I97I). The diplococcus types were clearly motile when observed under the microscope. Motility of methanogenic cocci has been reported only in Methanococcus vannielii (Wolfe, 197I), but possibly it has not been observed before with other batch cultures because these conditions are not so conducive as the chemostat conditions for expression of this property. We do not discard the possibility that Methanococcus vannielii was present. Attempts to isolate the methanogenic bacteria in pure culture have so far failed.

\section{Growth of a mixed culture on glucose}

Once the characteristics of the formate-utilizing organisms were known, particularly the maximum specific growth rate, we tried to constitute a defined mixed culture able to grow on glucose. We thought that a possible associate for the methanogenic types could 

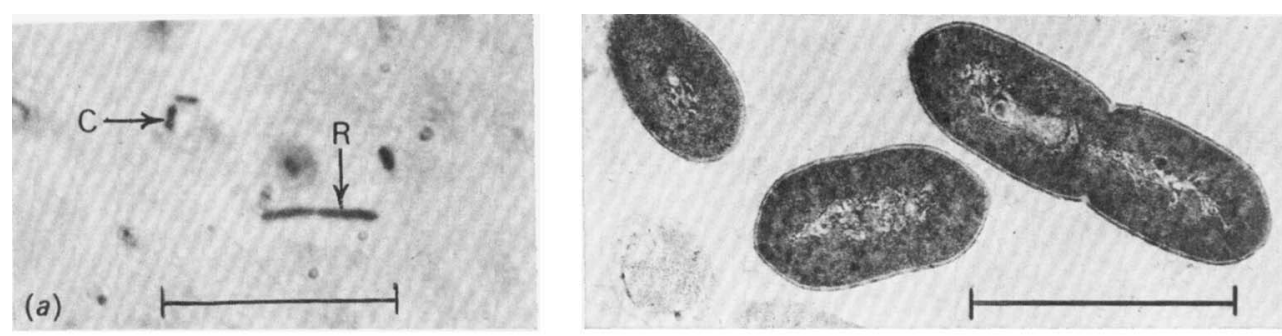

(b)

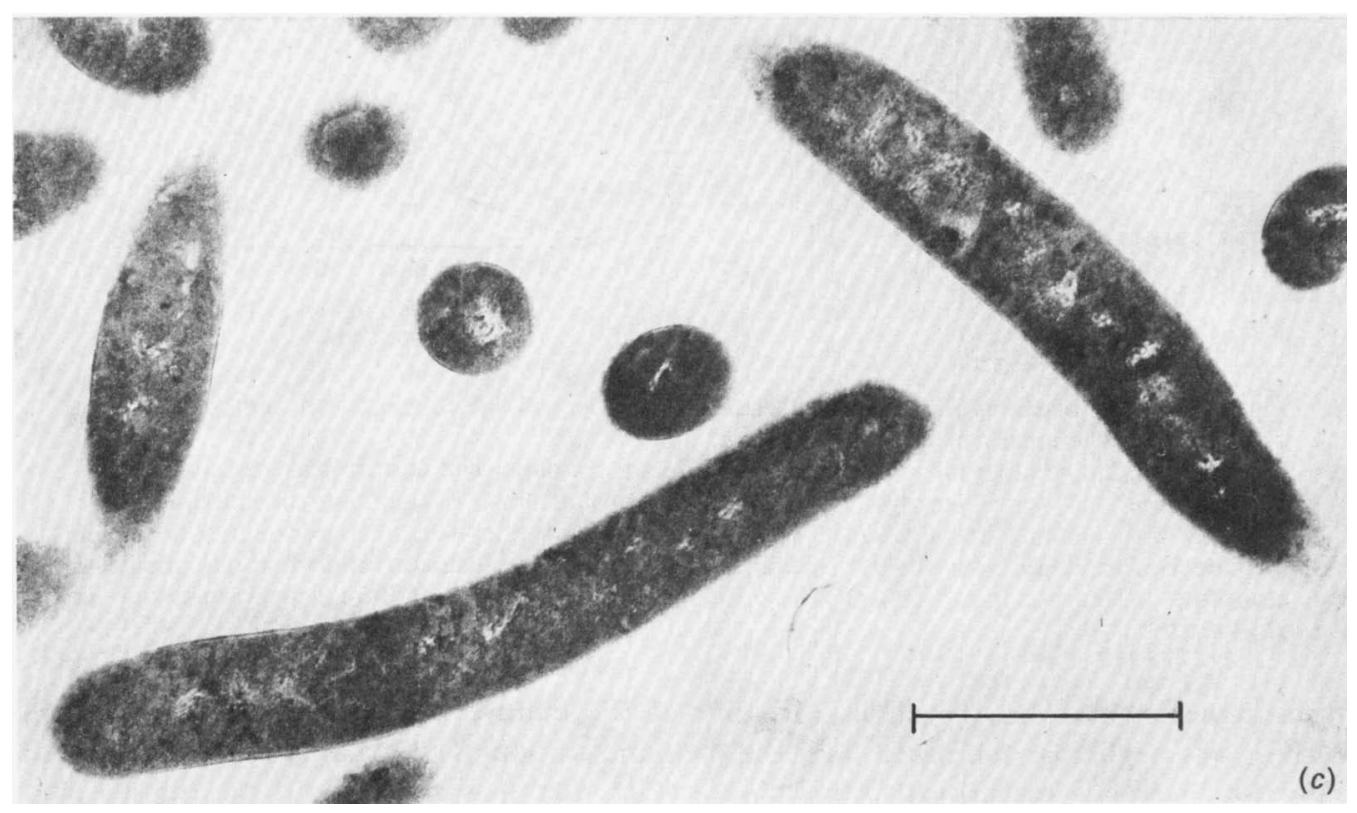

Fig. 3. (a) Phase contrast photograph of a sample of methanogenic culture from a steady-state culture growing on formate. The long rods (R) resemble Methanobacterium formicicum and the cocci $(\mathrm{C})$ are like Methanobacterium ruminantium. Bar marker represents $\mathrm{io} \mu \mathrm{m}$. (b) Electron micrograph of bacteria resembling Methanobacterium ruminantium from a chemostat culture growing on formate. Bar marker represents $\mathrm{I} \mu \mathrm{m}$. (c) Electron micrograph of bacteria resembling Methanobacterium formicicum from a chemostat culture growing on formate. Bar marker represents I $\mu \mathrm{m}$.

be one of the Enterobacteriaceae, such as Escherichia coli, which includes formate as well as $\mathrm{H}_{2}$ and $\mathrm{CO}_{2}$ among its fermentation products. For this purpose we grew a culture of $E$. coli in the chemostat on the same minimal medium plus glucose and a large $(50 \%, \mathrm{v} / \mathrm{v})$ inoculum of the 'formate' culture was added. In less than $48 \mathrm{~h}$ at $D=0.039 \mathrm{~h}^{-1}, E$. coli disappeared and another member of the Enterobacteriaceae was the only organism present which could grow aerobically or anaerobically on either MacConkey agar or peptone agar plates. On examination of the original 'formate' culture, we found that the same facultative anaerobe was present at about 1000 to 1500 organisms $\mathrm{ml}^{-1}$.

The facultative anaerobe isolated was a Gram-negative, short rod with the following biochemical characteristics: utilization of glucose + , lactose + , dulcitol - , citrate + (weak), urea - ; formation of gas from glucose + , indole - , hydrogen sulphide + ; activities of lysine decarboxylase - , ornithine decarboxylase - , phenylalanine deaminase -. This organism, termed isolate I, was identified as Citrobacter freundii.

To check whether the citrobacter isolate I was an accidental contaminant or had some relationship with the methanogenic bacteria, a new chemostat was set up to re-isolate a formate-utilizing culture from a new sample of sludge (taken from a different digester 


\section{Table I. Fermentation products from glucose in chemostat steady states}

For the citrobacter culture, glucose was supplied at $44 \mathrm{~mm}$ and $D$ was $0.09 \mathrm{~h}^{-1}$ whilst for the methanogenic association culture, glucose was supplied at $40 \mathrm{~mm}$ and $D$ was $0.039 \mathrm{~h}^{-1}$. No residual glucose was detectable in either culture. The values given for the fermentation products are the means for two samples taken at different times from the same culture during a steady state defined by a constant rate of methane production.

\begin{tabular}{|c|c|c|c|c|c|c|c|}
\hline \multirow[b]{2}{*}{ Culture } & \multirow{2}{*}{$\begin{array}{c}\text { Carbon } \\
\text { recovery } \\
(\%)^{*}\end{array}$} & \multicolumn{5}{|c|}{ Product (mol per $100 \mathrm{~mol}$ fermented glucose) } & \multirow{2}{*}{$\begin{array}{l}10^{-8} \times \text { Cell } \\
\text { count }\left(\mathrm{ml}^{-1}\right)\end{array}$} \\
\hline & & Acetate & Formate & Ethanol & Lactate & Methane & \\
\hline Citrobacter (isolate I) & 72 & $\operatorname{Ir} 2$ & 25 & $53 \cdot 7$ & 25 & 0 & 40 (viable) \\
\hline $\begin{array}{l}\text { Methanogenic association } \\
\text { culture }\end{array}$ & $\begin{array}{l}98 \\
\quad * \mathrm{Th} \\
+\mathrm{Ae}\end{array}$ & $\begin{array}{l}265 \\
\text { s does } \\
\text { obic c }\end{array}$ & $\begin{array}{l}\text { include } \\
\text { t. }\end{array}$ & ell ca & 5 & $27 \cdot 2$ & $\begin{array}{l}2 \cdot 3(\text { viable }) \dagger \\
7 \cdot 0(\text { total })\end{array}$ \\
\hline
\end{tabular}

in the same sewage plant). A similar culture was selected and again we found a facultative anaerobe which belonged to the genus Citrobacter. This second isolate (IOc), which differed from $I$ in that it was indole + and ornithine decarboxylase + , was identified as Citrobacter diversus; isolate Ioc has been deposited as culture no. II $28 \mathrm{I}$ with the National Collection of Industrial Bacteria, Torry Research Station, Aberdeen.

The steady state in formate culture (as measured by methane production and aerobic counts in MacConkey agar) was stable for several hundreds of volume changes (i.e. over several months) which suggested that there was a special relationship between citrobacter and methanogenic bacteria in this system. One advantage of this relationship would be that the facultative anaerobe would remove traces of oxygen in the cultures to provide the necessary redox potential for the methanogenic species to multiply.

\section{Fermentation products of citrobacter and of the citrobacter-methanogenic bacteria in chemostat culture on glucose}

Fermentation balances of citrobacter isolate $I$ and of the mixed culture on glucose are given in Table I. The major products in the pure culture of citrobacter were acetate, formate, ethanol and lactate. There was an unestimated amount of $\mathrm{CO}_{2}$, and an acid product which was not characterized although it eluted as succinate from a silicic acid column. As the total count in the methanogenic association culture was less than in the pure citrobacter culture, the growth of citrobacter on glucose was probably modified by the presence of the other bacteria. However, the interpretation of the counts of the mixed culture, using a Coulter counter, is complicated by the presence of chains of cells and cells of different sizes. If we consider formate as the precursor of methane we would expect only $6.25 \mathrm{~mol}$ methane to be formed in the process (I mol formate gives $0.25 \mathrm{~mol}$ methane). However, there was a fourfold increase in the production of methane; thus it seems that the oxidation of formate was linked to the reduction of $\mathrm{CO}_{2}$, thus shifting the equilibrium against the production of lactate and ethanol.

These results confirm the Hungate hypothesis (1966) for rumen fermentation, i.e. the 'normal' reduced products disappear when a hydrogen sink, such as the methanogenic bacteria, is present, with a concomitant rise in the concentration of the oxidized products (acetate). Wolin (I974) observed that $\mathrm{H}_{2}$ and formate, which are normal products of cellulose fermentation by Ruminococcus flavefasciens, disappeared completely when it was cocultured with Methanobacterium ruminantium; thus this type of behaviour seems to be widespread in several ecosystems. 
Table 2. Products of the citrobacter (isolate I) spent glucose medium fed into a chemostat culture of the methanogenic bacteria association at $D=0.093 h^{-1}$

\begin{tabular}{lccccc} 
& \multicolumn{4}{c}{ Product $\left[\mu\right.$ mol $\left.(\mathrm{ml} \text { medium })^{-1}\right]$} & in steady state \\
& Lactate $_{\text {Letate }}$ & Formate & Ethanol & $\mathrm{CH}_{4}$ \\
Supply of spent medium* & 3.88 & 25 & 4.5 & 13.0 & 0 \\
Medium in culture vessel & $<$ O.I & 20 & 0 & 4.3 & 2.6
\end{tabular}

* The sterile spent medium was conserved for some weeks and as a result showed some deviation in the proportions of products from those given in Table $\mathrm{I}$.

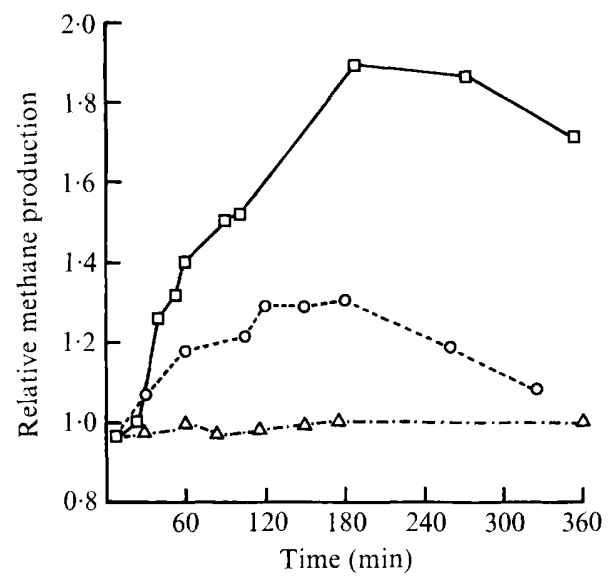

Fig. 4

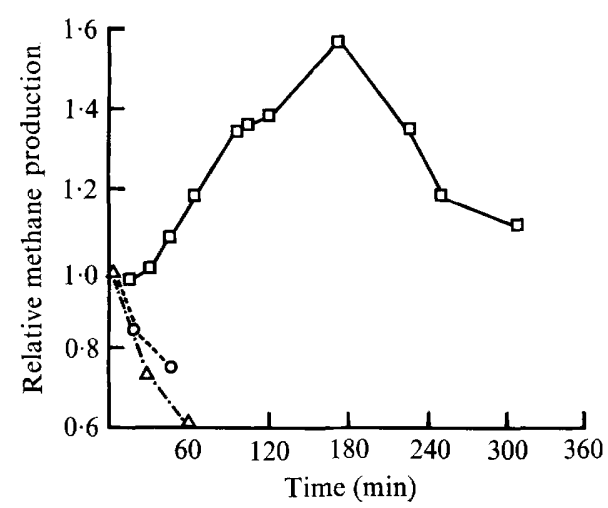

Fig. 5

Fig. 4. Effects of the main products of glucose fermentation by citrobacter on methane production, in the presence of formate, by the methanogenic association culture. A methanogenic chemostat culture fed with formate $(66 \mathrm{~mm})$ was set up and a steady state obtained. At zero time either ethanol, acetate or lactate was injected into the culture to give $25 \mathrm{~mm}$-ethanol $(\triangle)$, IO mM-acetate ( $\bigcirc)$ or $25 \mathrm{~mm}$-lactate $(\square)$. The relative methane production is the amount of methane in the gas phase relative to that from the formate-grown culture in the steady state.

Fig. 5. Effects of the main products of glucose fermentation by citrobacter on methane production by a formate-limited methanogenic association culture when formate addition was stopped. A methanogenic chemostat culture fed with formate $(66 \mathrm{~mm})$ was set up and a steady state obtained. At zero time the formate addition was stopped and either ethanol, acetate or lactate was injected into the culture to give $25 \mathrm{~mm}$-ethanol $(\triangle)$, ro mM-acetate $(O)$ or 25 mM-lactate $(\square)$. The relative methane production is the amount of methane in the gas phase relative to that from the formate-grown culture in the steady state.

\section{Production of methane from the products of citrobacter fermentation of glucose}

To see if the symbiotic relationship could be separated into two stages (as in a two-stage process) the fermentation products (excluding the gases) of the citrobacter were collected, sterilized by filtration and fed to the methanogenic mixed culture that had been growing continuously on formate. The composition of the spent medium and the products from the spent medium after growth of the methanogenic bacteria (Table 2) show that some of the acetate and ethanol was used by the methanogenic culture, but the lactate and formate were virtually completely metabolized and so could have been the substrates which limited methane production. It has been repeatedly reported (Jeris \& McCarthy, I965; Smith \& Mah, I966; Cappenberg \& Prins, 1974) that acetate is an important precursor of methane; however, pure cultures on acetate seem to grow poorly (Wolfe, 1971). Pretorius (1972) used continuous culture with extremely long residence times (20 days) and showed that acetate alone could not keep the culture growing; formate was 
Table 3. Utilization of acetate in the presence of formate by the methanogenic association culture in the chemostat at $D=0.095 h^{-1}$

\begin{tabular}{lccc}
\multicolumn{1}{c}{ Medium } & $\begin{array}{c}\text { Formate } \\
(\mathrm{mm})\end{array}$ & $\begin{array}{c}\text { Acetate } \\
(\mathrm{mm})\end{array}$ & $\begin{array}{c}\mathrm{CH}_{4} \text { produced } \\
(\mathrm{mmol} \text { per } 1 \text { feed })\end{array}$ \\
In feed & 40 & 0 & 0 \\
In culture & $0 \cdot 0$ & 0 & $6 \cdot 7$ \\
In feed & 40 & $40^{*}$ & 0 \\
In culture & 0.0 & 30 & $\mathrm{II} \cdot 0$ \\
& $*$ Not all consumed, see text. &
\end{tabular}

needed to allow metabolism of the acetate. Zeikus et al. (1975), using pure cultures, showed that acetate could be used if $\mathrm{H}_{2}$ or $\mathrm{CO}_{2}$ plus $\mathrm{H}_{2}$ were present in the culture.

We then studied the influence of each product arising from glucose metabolism by citrobacter (isolate I). We used the method of Mateles \& Battat (1974) who introduced the compounds under test directly into the continuous culture vessel. Each product was added separately to a methanogenic association culture grown on formate in a chemostat.

The results (Fig. 4) show that, in the presence of formate, there was an immediate increase in methane production when acetate or lactate was added to the vessel; ethanol, on the other hand, had no effect. Since these experiments were of short duration compared with the bacterial doubling times, the selection of a bacterial species specializing in the use of added substrate is precluded. When the formate flow was stopped the response was quite different (Fig. 5); methane production ceased immediately, either with acetate or ethanol, but was maintained by lactate. By integration, $5 \mathrm{mmol}$ lactate produced $2.97 \mathrm{mmol}$ methane during the experiment, i.e. a yield of $0.59 \mathrm{~mol}$ methane per mol lactate. This result is in good agreement with the theoretical prediction assuming lactate is metabolized via pyruvate according to: 2 lactate $\rightarrow 2$ acetate $+\mathrm{CO}_{2}+\mathrm{CH}_{4}$ which would give $0.5 \mathrm{~mol}$ methane per mol lactate. However, as acetate is being produced, it could itself be used and this would account for the extra methane. This indicates yet another difference in the behaviour of acetate and lactate. It now seems that acetate is co-metabolized and requires the presence of some other carbon source such as formate. Indeed, when an experiment was set up in a chemostat in which the formate was replaced by a mixture of formate and acetate, the extent to which acetate could be used required a ratio of formate to acetate of $4:$ I since excess acetate was not used (Table 3). Pretorius (1972) used a ratio of approximately 5: I formate to acetate and found that acetate was completely metabolized; he made no comment on this and, moreover, the results of Zeikus et al. (1975) show that there was no linear correlation between the concentration of acetate and the extent of its utilization.

\section{General discussion}

The continuous enrichment technique, under anaerobic conditions with formate as the sole carbon and energy source, provided a convenient means for isolating a mixed bacterial population which was predominantly methanogenic. The apparent presence of two methanogenic species (rods and cocci) in the formate-grown culture suggests that they are interdependent since, from mixed culture theory (Pirt, 1975), one species would probably be washed out if they both competed for the formate.

In the mixed population grown on formate, only a small proportion ( $\mathrm{I}$ in $10^{5}$ ) was citrobacter. However, this became a major member of the population when glucose was the carbon source. In the mixed population, glucose is degraded by the citrobacter via fermentation whilst the methanogenic bacteria act as a hydrogen sink which prevents the accumulation of reduced products so that the end products are mainly methane and acetate. 
The association of citrobacter with the methanogenic bacteria appeared to be very stable in that the citrobacter population was not washed out of the culture with formate as the sole carbon source even after the culture volume in the chemostat had been replaced several hundred times over a 10 month period. This suggests that a mechanism may have evolved in this association, for example growth of the citrobacter on a minute amount of lytic products of the methanogens (about $\mathrm{I} \mathrm{ng} \mathrm{ml^{-1 }}$ would be sufficient), to maintain the citrobacter as an agent for the potential degradation of carbohydrate to substrates for the methanogens. Such an association of species could be an effective means for cooperative use of their gene pool.

The role of the citrobacter may be specific to a minimal inorganic medium with glucose as the carbon and energy source. In more complex environments with different main carbon sources such as amino acids instead of glucose, other organisms may substitute for the citrobacter.

We are puzzled by the role of lactate as a sole carbon source which can be converted to methane at the maximum rate without lag in the formate-grown culture or methanogens. This indicates that either the lactate utilizer is one of the more numerous members of the association or is a highly active member present in small numbers. In contrast, acetate could be metabolized only with another suitable energy source such as formate.

The citrobacter cultures were independently classified by Dr Mary Hedberg at the New York State Department of Health Laboratories, Albany, New York, U.S.A. F. Siñeriz was supported by a fellowship from the Consejo Nacional de Investigaciones Científicas y Técnicas, Argentina.

\section{REFERENCES}

Barker, S. B. \& Summerson, W. H. (I94I). The colorimetric determination of lactic acid in biological material. Journal of Biological Chemistry I38, 535-544.

Cappenberg, Th. E. \& Prins, R. A. (I974). Interrelations between sulfate-reducing and methaneproducing bacteria in bottom deposits of a freshwater lake. III. Experiments with ${ }^{14} \mathrm{C}$-labelled substrates. Antonie van Leeuwenhoek 40, 457-469.

Ferry, J. G. \& Wolfe, R. S. (1976). Anaerobic degradation of benzoate to methane by a microbial consortium. Archives of Microbiology 107, 33-40.

Hungate, R. E. (1966). The Rumen and Its Microbes. New York: Academic Press.

Jeris, J. S. \& McCarthy, P. L. (I965). The biochemistry of methane fermentation using $\mathrm{C}^{\mathbf{1 4}}$ tracers. Journal of the Water Pollution Control Federation 37, 178-192.

Mateles, R. I. \& Battat, E. (I974). Continuous culture used for media optimization. Applied Microbiology 28, 90I-905.

PIRT, S. J. (1975). Principles of Microbe and Cell Cultivation. Oxford: Blackwell Scientific Publications.
PIRT, S. J. \& Callow, D. S. (I964). Continuous flow culture of the ERK and L types of mammalian cells. Experimental Cell Research 33, 413-421.

Pretorius, W. A. (1972). The effect of formate on the growth of acetate-utilizing methanogenic bacteria. Water Resources 6, $1213-1217$.

RAMSEY, H. A. (I963). Separation of organic acids in blood by partition chromatography. Journal of Dairy Science 46, 480-483.

SMITH, P. H. \& MAH, R. A. (1966). Kinetics of acetate metabolism during sludge digestion. Applied Microbiology 14, 368-371.

WoLFE, R. S. (I97I). Microbial formation of methane. Advances in Microbial Physiology 6, 107-146.

Wolin, M. J. (1974). Metabolic interactions among intestinal microorganisms. American Journal of Nutrition 27, 1320-1328.

Zeikus, J. G. \& BoweN, V. G. (1975). Comparative ultrastructure of methanogenic bacteria. Canadian Journal of Microbiology 21, I 2 I-I 29.

Zeikus, J. G., Weimer, P. J., Nelson, D. R. \& DANIELS, L. (I975). Bacterial methanogenesis: acetate as a methane precursor in pure culture. Archives of Microbiology 104, 1 29-1 34. 